\title{
Traumatic brain injury in patients aged $\geq 65$ years versus patients aged $\geq 80$ years: a multicenter prospective study of mortality and medical resource utilization
}

\author{
SooJin Bae', Sung Wook Song'2, Woo Jeong Kim², YoungJoon Kang ${ }^{3}$, \\ Kyeong Won Kang ${ }^{2}$, Chang Bae Park', Jeong Ho Kang ${ }^{2}$, Ji Hwan Bu', \\ Sung Kgun Lee², Seo Young Ko' \\ 'Department of Emergency Medicine, Jeju National University Hospital, Jeju, Korea \\ ${ }^{2}$ Department of Emergency Medicine, Jeju National University School of Medicine, Jeju, Korea \\ ${ }^{3}$ Departments of Medical Education, Jeju National University School of Medicine, Jeju, Korea
}

Objective This study aimed to determine whether there is a difference in mortality and medical resource utilization between geriatric (aged $\geq 65$ years) and super-geriatric patients (aged $\geq 80$ years) with traumatic brain injury (TBI).

Methods We obtained comprehensive data (demographics, injury characteristics, injury severities, and outcomes) of geriatric and super-geriatric TBI patients from an emergency departmentbased injury surveillance system database from 2011 to 2016. Multivariate logistic regression analysis was performed to compare the mortality and nonroutine discharge (NRDC) status between both groups.

Results Among 442,533 TBI patients, 48,624 were older than 65 years. A total of 48,446 patients $(37,140$ geriatric and 11,306 super-geriatric) without exclusion criteria were included in the final analysis. Both overall in-hospital mortality (adjusted odds ratio, 1.88; 95\% confidence interval $[\mathrm{Cl}], 1.28$ to $2.74 ; \mathrm{P}=0.001$ ) and NRDC (adjusted odds ratio, $1.35 ; 95 \% \mathrm{Cl}, 1.07$ to 1.71 ; $P=0.011$ ) were significantly higher in the super-geriatric group. In the stratified analysis, there were no significant differences in NRDC rate for all stratifications of treatment timing (emergency department vs. ward admission), but mortality remained to be significant for all stratifications.

Conclusion Super-geriatric TBI patients showed a significantly higher risk-adjusted overall mortality and more inadequate medical resource utilization than did geriatric TBI patients. However, super-geriatric patients were more likely to undergo NRDC after admission; thus, further research about age-related health inequalities is needed in the treatment of super-geriatric patients.

Keywords Geriatrics; Brain injuries, traumatic; Mortality
eISSN: 2383-4625

Received: 28 April 2020

Revised: 15 June 2020

Accepted: 16 June 2020

Correspondence to: Sung Wook Song Department of Emergency Medicine, Jeju National University School of Medicine, 15 Aran 13-gil, Jeju 63241, Korea

E-mail: sungwook78@jejunu.ac.kr ORCID

https://orcid.org/0000-0002-7056-6179

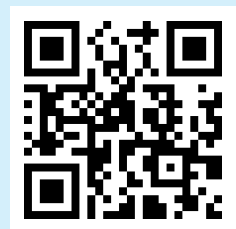

How to cite this article:

Bae SJ, Song SW, Kim WJ, Kang YJ, Kang KW, Park CB, Kang JH, Bu JH, Lee SK, Ko SY. Traumatic brain injury in patients aged $\geq 65$ years versus patients aged $\geq 80$ years: a multicenter prospective study of mortality and medical resource utilization. Clin Exp Emerg Med 2021;8(2):94-102. https://doi. org/10.15441/ceem.20.045
This is an Open Access article distributed under the terms of the Creative Commons Attribution Non-Commercial License (https:// creativecommons.org/licenses/by-nc/4.0/). 


Capsule
$\begin{aligned} & \text { What is already known } \\ & \text { Summary } \\ & \text { Geriatric patients (age older than } 65 \text { years) are a rapidly growing group as compared with other age groups, and "super- } \\ & \text { geriatric" patients (aged } 80 \text { years or older) are becoming a new age subgroup. However, relatively few studies investi- } \\ & \text { gated the outcomes of super-geriatric traumatic brain injury (TBI) patients. } \\ & \text { What is new in the current study } \\ & \text { Super-geriatric TBI patients have a significantly higher risk-adjusted overall mortality and more inadequate medical } \\ & \text { resource utilization than do geriatric TBI patients. Furthermore, in the stratified analysis, the statistical significance of } \\ & \text { medical resource utilization differed when stratified by the timing of treatment. }\end{aligned}$

\section{INTRODUCTION}

With increasing longevity and falling birth rates, the demographic trend is toward an older population. The United Nations defines an "aging society" as one in which $>7 \%$ of the population are aged $\geq 65$ years. In 2000, elderly individuals constituted $7.2 \%$ of the South Korean population; this number has doubled to $14.3 \%$ in 2018. ' South Korea is expected to become a post-aged society in 30 years, compared with France in 155 years, the United States in 88 years, Germany in 78 years, and Japan in 36 years. ${ }^{2}$

Geriatric individuals are prone to injuries because of reduced body control function associated with aging. Among injured geriatric patients, traumatic brain injury (TBI) has been a significant cause of high mortality and disability rates. ${ }^{3,4}$ The incidence of TBI in geriatric patients visiting the emergency department (ED) was reported to be about 494 per 100,000 people in the United States, and this number has been expected to rise continuously. ${ }^{5}$ Meanwhile, super-geriatric patients, defined as those aged $\geq 80$ years, have been emerging as a new population group, distinguishable from the conventional geriatric group aged $\geq 65$ years. ${ }^{1,3,4}$

Several previous studies have shown that elderly patients with TBI have a worse functional outcome than younger patients with TBI of the same or less severity. ${ }^{6,7}$ However, most of these studies focused on geriatric patients, and relatively few studies have investigated the outcomes of super-geriatric TBI patients.

There is limited evidence to generalize whether increased age is a risk factor for TBI between geriatric patients and super-geriatric patients. In addition, the results of treatment and the utilization of medical resources for super-geriatric patients with TBI are also not well known. This study, therefore, aimed to compare the mortality rates and medical resource utilization between geriatric and super-geriatric patients visiting the ED.

\section{METHODS}

\section{Study design}

This nationwide multicenter prospective registry study used data from an emergency department-based surveillance system (EDISS) database to investigate injury epidemiology at $20 \mathrm{EDs}$ of tertiary hospitals operated by the Korea Centers for Disease Control and Prevention. The study was carried out with a waiver of informed consent with approval from the institutional review board of Jeju National University Hospital (2020-03-008).

\section{Study population}

The eligible population included all patients who visited the EDs due to TBI between January 2011 and December 2016. TBI was defined as any of the diagnostic codes of the International Classification of Diseases, 10th edition, that met the Korea Centers for Disease Control and Prevention TBI definition (S01.0-S01.9, S02.0-S02.1, S02.3, S02.7-02.9, S04.0, S06.0-S06.9, S07.0-07.1, S07.8-S07.9, S09.7-S09.9, T01.0-T02.0, T04.0, T06.0), regardless of whether other injury diagnoses were present.

The study population consisted of a subset of TBI patients aged $\geq 65$ years from the eligible population and was divided into two groups: geriatric (aged 65-79 years) and super-geriatric (aged $\geq 80$ years). Patients whose age or final clinical outcome could not be determined or those who died on arrival at the ED were excluded from the final analysis.

\section{Data collection}

We analyzed the data from the EDISS database, which were collected by ED physicians at the 20 participating hospitals. The EDISS registry included comprehensive information on TBI, such as patient demographics (sex, insurance type, vital signs, and mental status), injury characteristics (intention, mechanism, activities, places, anatomical site of injury, emergency medical service [EMS] 
usage, and alcohol-related injury), injury severity, emergency care process, diagnosis, treatment, disposition (discharge, interhospital transfer, admission, death, etc.) at the ED, and disposition after hospital admission (discharge, interhospital transfer, death, etc.). The injury severity variable included the revised trauma score and excess mortality ratio-adjusted injury severity score (EMR-ISS). The EMR-ISS is a scoring method to measure injury severity in large-scale patient data; it was developed in 2009 based on the International Classification of Diseases, 10th edition.

The primary outcome was a binary indicator for in-hospital mortality. The secondary outcomes were unnecessary interhospital transfer and abnormal discharge (against medical advice or hopeless discharge), which reflect nonroutine discharge (NRDC) in terms of the utilization of medical resources.

\section{Statistical analysis}

We compared the baseline demographic and injury characteristic variables between the geriatric and super-geriatric groups, using either the Student t-test, Wilcoxon rank-sum test, chi-squared test, or Fisher exact test, as appropriate.

Descriptive statistics are presented as frequencies and percentages for comparing categorical variables, and means with standard deviations or medians with interquartile ranges for comparing continuous variables, depending on the distribution.

The patient's age was treated as a dichotomous variable for both geriatric and super-geriatric patients with TBI and then as an ordinal categorical variable at a 5-year interval.

Univariate logistic regression was used to analyze dichotomous primary or secondary outcomes. After that, multivariate logistic regression was used to adjust for potential confounders and to identify whether aging affected mortality, interhospital transfer, and NRDC between geriatric and super-geriatric TBI patients. Results of the logistic regression analyses were further stratified by ED and ward admission to determine if associations were modified by the timing of treatment. We also conducted additional multiple comparisons treating age as an ordinal categorical variable at a 5-year interval.

All statistical analyses were performed using Stata ver. 14.0 (StataCorp., College Station, TX, USA) and using a two-tailed test with a statistical significance level of $\mathrm{P}<0.05$.

\section{RESULTS}

\section{Study flow}

Among the 442,533 TBI patients registered in the EDISS, 48,624 were aged $\geq 65$ years. Of these eligible patients, 178 were excluded because of death on arrival (102 patients) and mortality of unknown cause (76 patients). A total of 48,446 TBI patients, consisting of 37,140 geriatric patients and 11,306 super-geriatric patients, were included in the final analysis (Fig. 1).

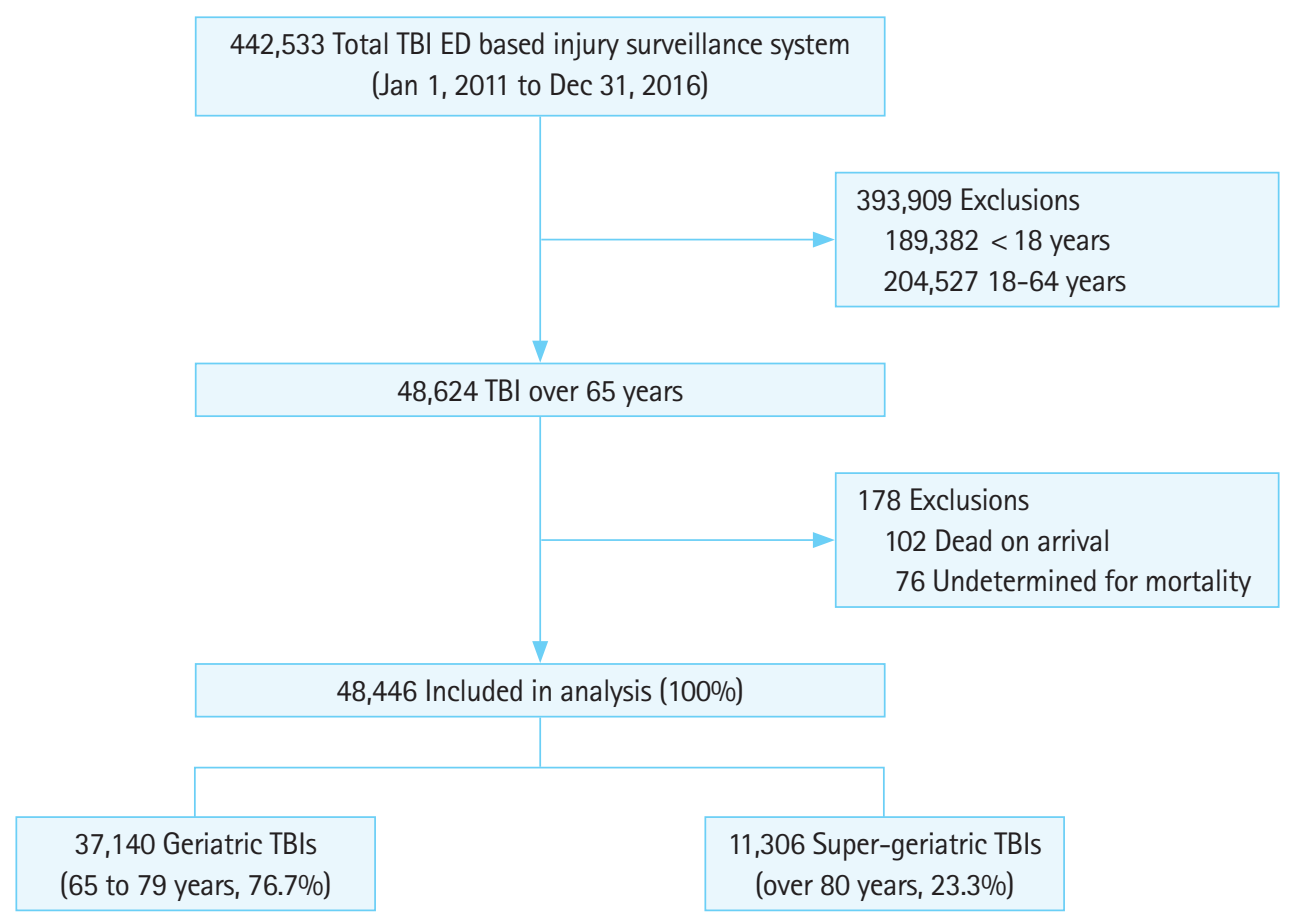

Fig. 1. Flow diagram of patient enrollment. TBI, traumatic brain injury; ED, emergency department. 


\section{Baseline demographics}

Table 1 provides a comparison of demographic characteristics between the geriatric and super-geriatric groups. The proportion of females was significantly higher in the super-geriatric group than in the geriatric group (39.7\% vs. $53.8 \%, P<0.001)$, and there was a significant difference in insurance type $(P<0.001)$ between both groups.

Regarding arrival at the ED, there were statistically significant differences between the geriatric and super-geriatric groups in terms of systolic blood pressure, diastolic blood pressure, and AVPU (alert, voice, pain, unresponsive) mental status. However, there were no statistically significant differences in pulse rate, respiration rate, and mean Glasgow coma scale score between both groups.

Based on initial vital signs, the average revised trauma score was not significantly different between the geriatric and supergeriatric groups ( $7.64 \pm 0.86$ and $7.66 \pm 0.80$, respectively; $P=0.107)$. However, in the geriatric group, the mean EMR-ISS was $21.1 \pm 16.1$, which was significantly higher than $20.5 \pm 15.2$ in the super-geriatric group $(P=0.012)$.

For the emergency care process at the ED, there was no significant difference between the two groups in terms of length of stay, but there was a significant difference in the tendency of patients to receive treatment.

\section{Injury characteristics}

The injury characteristics of the study population are shown in Table 2, while the number and anatomical site of injury are summarized in Table 3. We found statistical differences in factors at the time of the injury, such as intention, mechanism, activity, place, alcohol-related injury, EMS usage, and isolated TBI $(\mathrm{P}<0.001)$. We also found statistical differences in anatomical injury site except for the head and elbow/forearm between both groups.

In particular, geriatric patients were more likely to have an intentional injury, motor vehicle collision as the mechanism of injury, a paid or leisure/play activity, road as the place of injury, and alcohol-related injury than super-geriatric patients. On the other hand, super-geriatric patients were more likely to experience an unintentional injury, fall/slip as the mechanism of injury, a vital activity, home/residence as the place of injury, EMS usage, and an isolated TBI than geriatric patients.

\section{Mortality and medical resource utilization}

The descriptive statistics for mortality and medical resource utilization (admission, interhospital transfer, NRDC) are presented in Table 4. The univariate and multivariate logistic regression analyses of primary and secondary outcomes are presented in Table 5 , and the results between the two groups were stratified according

Table 1. Demographic characteristics between the geriatric and super-geriatric groups

\begin{tabular}{|c|c|c|c|c|}
\hline & Geriatric $(n=37,140)$ & Super-geriatric $(n=11,306)$ & Total $(n=48,446)$ & P-value \\
\hline Sex, female & $14,737(39.7)$ & $6,084(53.8)$ & $20,821(43.0)$ & $<0.001$ \\
\hline Insurance & & & & $<0.001$ \\
\hline National health insurance & $27,441(73.9)$ & 8,908 (78.8) & $36,349(75.0)$ & \\
\hline Automobile insurance & $6,554(17.7)$ & $1,218(10.8)$ & $7,772(16.0)$ & \\
\hline Medical care assistance & $1,968(5.3)$ & $931(8.2)$ & $2,899(6.0)$ & \\
\hline Others & $1,177(3.2)$ & $249(2.2)$ & $1,426(2.9)$ & \\
\hline $\mathrm{SBP}(\mathrm{mmHg})$ & $140.7 \pm 30.7$ & $144.8 \pm 32.0$ & $141.7 \pm 31.1$ & $<0.001$ \\
\hline $\mathrm{DBP}(\mathrm{mmHg})$ & $80.0 \pm 17.5$ & $79.1 \pm 17.6$ & $79.8 \pm 17.5$ & $<0.001$ \\
\hline Pulse rate $(/ \mathrm{min})$ & $80.7 \pm 16.4$ & $81.0 \pm 16.3$ & $80.8 \pm 16.4$ & 0.079 \\
\hline Respiration rate (/min) & $19.0 \pm 3.4$ & $19.0 \pm 3.3$ & $19.0 \pm 3.4$ & 0.205 \\
\hline Body temperature $\left({ }^{\circ} \mathrm{C}\right)$ & $36.3 \pm 2.2$ & $36.4 \pm 1.8$ & $36.3 \pm 2.1$ & 0.080 \\
\hline Glasgow coma scale & $14.3 \pm 2.4$ & $14.3 \pm 2.3$ & $14.3 \pm 2.4$ & 0.335 \\
\hline Mental status & & & & 0.005 \\
\hline Alert & 27,011 (88.9) & $8,370(88.5)$ & 35,381 (88.8) & \\
\hline Verbal & $1,652(5.4)$ & $559(5.9)$ & $2,211(5.6)$ & \\
\hline Painful & $1,080(3.6)$ & 367 (3.9) & $1,447(3.6)$ & \\
\hline Unresponsive & $659(2.2)$ & 161 (1.7) & $820(2.1)$ & \\
\hline RTS & $7.64 \pm 0.86$ & $7.66 \pm 0.80$ & $7.65 \pm 0.84$ & 0.107 \\
\hline EMR-ISS & $21.1 \pm 16.1$ & $20.5 \pm 15.2$ & $20.9 \pm 15.9$ & $<0.001$ \\
\hline Operation, yes & $2,747(12.8)$ & 760 (11.4) & 3507 (12.5) & 0.002 \\
\hline ED LOS (hr): p50 (p25, p75) & $3.3(1.8,5.9)$ & $3.3(1.9,5.8)$ & $3.3(1.8,5.9)$ & 0.117 \\
\hline
\end{tabular}

Values are presented as number (\%) or mean \pm stadard deviation.

SBP, systolic blood pressure; DBP, diastolic blood pressure; RTS, revised trauma score; EMR-ISS, excess mortality ratio-adjusted injury severity score; ED, emergency department; LOS, length of stay. 
to ED, ward, and overall admission.

The overall mortality and NRDC rates were significantly higher

Table 2. Injury characteristics between the geriatric and super-geriatric groups

\begin{tabular}{|c|c|c|c|c|}
\hline & $\begin{array}{c}\text { Geriatric } \\
(n=37,140)\end{array}$ & $\begin{array}{c}\text { Super-geriatric } \\
(n=11,306)\end{array}$ & $\begin{array}{c}\text { Total } \\
(n=48,446)\end{array}$ & P-value \\
\hline Intentional injury & $931(2.5)$ & $140(1.2)$ & $1071(2.2)$ & $<0.001$ \\
\hline Mechanisms & & & & $<0.001$ \\
\hline Fall/slip down & $21,155(60.0)$ & $8,123(71.9)$ & $29,278(60.4)$ & \\
\hline MVC & $10,156(27.4)$ & $1,878(16.6)$ & $12,034(24.8)$ & \\
\hline Blunt & $4,303(11.6)$ & $933(8.3)$ & $5,236(10.8)$ & \\
\hline Penetrating & 805 (2.2) & $139(1.2)$ & 944 (2.0) & \\
\hline Others & 721 (1.9) & $233(2.1)$ & 954 (2.0) & \\
\hline Activities & & & & $<0.001$ \\
\hline Paid work & $2,807(7.6)$ & $220(2.0)$ & $3,027(6.3)$ & \\
\hline Unpaid work & 5,568 (15.0) & $1,456(12.9)$ & $7,024(14.5)$ & \\
\hline Vital activity & $16,948(45.6)$ & $6,972(61.7)$ & $23,920(49.4)$ & \\
\hline Leisure or play & $9,072(24.4)$ & $1,979(17.5)$ & $11,051(22.8)$ & \\
\hline Others & 2745 (7.4) & $679(6.0)$ & $3,424(7.1)$ & \\
\hline Places & & & & $<0.001$ \\
\hline Home/residence & $12,876(34.7)$ & $6,019(53.2)$ & $18,895(39.0)$ & \\
\hline Road & $16,471(44.4)$ & 3,577 (31.6) & $20,048(41.4)$ & \\
\hline Commercial & 2989 (8.1) & 665 (5.9) & $3,654(7.5)$ & \\
\hline Hospital & $762(2.1)$ & $468(4.1)$ & $1,230(2.5)$ & \\
\hline Workplace & $1,499(4.0)$ & $122(1.1)$ & $1,621(3.4)$ & \\
\hline Unspecified & $2,543(6.9)$ & $455(4.0)$ & $2,998(6.2)$ & \\
\hline EMS usage & $15,848(42.7)$ & $5,201(46.0)$ & $21,049(43.5)$ & $<0.001$ \\
\hline Alcohol-related & $5,283(14.2)$ & $448(4.0)$ & $5,731(11.8)$ & $<0.001$ \\
\hline
\end{tabular}

Values are presented as number (\%).

MVC, motor vehicle collision; EMS, emergency medical service. in the super-geriatric group than in the geriatric group according to the timing of treatment (i.e., ED and ward admission). In particular, there were no significant differences in mortality and NRDC rates between both groups for ED admission ( $P>0.050)$, but significant differences in mortality and NRDC rates were found for admission in the ward $(\mathrm{P}<0.050)$ (Table 4).

In the logistic regression model with no covariates, the odds of overall mortality $(1.234, \mathrm{P}<0.001)$ and $\operatorname{NRDC}(1.086, \mathrm{P}=0.027)$ were significant. In the multivariate logistic regression model adjusted for covariates, the adjusted odds of overall mortality (1.680;

Table 3. Number and anatomical site of injury between the geriatric and super-geriatric groups

\begin{tabular}{|c|c|c|c|c|}
\hline & $\begin{array}{c}\text { Geriatric } \\
(n=37,140)\end{array}$ & $\begin{array}{c}\text { Super- } \\
\text { geriatric } \\
(n=11,306)\end{array}$ & $\begin{array}{c}\text { Total } \\
(n=48,446)\end{array}$ & P-value \\
\hline Isolated TBI & $24,830(66.9)$ & $7,835(69.3)$ & $32,665(67.4)$ & $<0.001$ \\
\hline \multicolumn{5}{|c|}{ Combined anatomical injury site } \\
\hline Neck & $1,901(5.1)$ & $392(3.5)$ & $2,293(4.7)$ & $<0.001$ \\
\hline Thorax & $2,741(7.4)$ & $648(5.7)$ & $3,389(7.0)$ & $<0.001$ \\
\hline $\begin{array}{l}\text { Abdomen, pelvis, and } \\
\text { lower back }\end{array}$ & $1,964(5.3)$ & $474(4.2)$ & $2,438(5.0)$ & $<0.001$ \\
\hline Shoulder and upper arm & $1,537(4.1)$ & $382(3.4)$ & $1,919(4.0)$ & $<0.001$ \\
\hline Elbow and forearm & $1,169(3.2)$ & $320(2.8)$ & $1,489(3.1)$ & 0.087 \\
\hline Wrist, hand, and finger & $1,058(2.9)$ & $400(3.5)$ & $1,458(3.0)$ & $<0.001$ \\
\hline Hip and thigh & $775(2.1)$ & $333(3.0)$ & $1,108(2.3)$ & $<0.001$ \\
\hline Knee and lower leg & $1,697(4.6)$ & $432(3.8)$ & $2,129(4.4)$ & 0.001 \\
\hline Ankle and foot & $328(0.9)$ & $74(0.7)$ & $402(0.8)$ & 0.019 \\
\hline
\end{tabular}

Values are presented as number (\%).

$\mathrm{TBI}$, traumatic brain injury.

Table 4. Mortality, admission, transfer, and NRDC rates between the geriatric and super-geriatric groups in the ED, ward, and overall

\begin{tabular}{|c|c|c|c|c|}
\hline & Geriatric & Super-geriatric & Total & P-value \\
\hline ED & $(n=37,140)$ & $(n=11,306)$ & $(n=48,446)$ & \\
\hline ED mortality & $560(1.5)$ & $195(1.7)$ & $755(1.6)$ & 0.103 \\
\hline Surviving patients in the ED & $(n=36,580)$ & $(n=11,111)$ & $(n=47,691)$ & \\
\hline Admission & $10,371(28.4)$ & $2,993(26.9)$ & $13,364(28.0)$ & 0.004 \\
\hline Transfer & $3,171(8.7)$ & $1,082(9.7)$ & $4,253(8.9)$ & 0.001 \\
\hline NRDC & $2,997(8.2)$ & $960(8.6)$ & $3,957(8.3)$ & 0.135 \\
\hline Ward & $(n=10,371)$ & $(n=2,993)$ & $(n=13,364)$ & \\
\hline Ward mortality & $845(8.2)$ & $328(11.0)$ & $1,173(8.8)$ & $<0.001$ \\
\hline Surviving patients in the ward & $(n=9,526)$ & $(n=2,665)$ & $(n=12,191)$ & \\
\hline Transfer & $2,317(24.3)$ & $698(26.2)$ & $3,015(24.7)$ & 0.048 \\
\hline NRDC & $200(2.1)$ & $80(3.0)$ & $280(2.3)$ & 0.006 \\
\hline Overall & $(n=37,140)$ & $(n=11,306)$ & $(n=48,446)$ & \\
\hline Overall mortality & $1,405(3.8)$ & $523(4.6)$ & $1,928(4.0)$ & $<0.001$ \\
\hline Surviving patients in the hospital & $(n=35,735)$ & $(n=10,783)$ & $(n=46,518)$ & \\
\hline Overall transfer & 2,955 (8.3) & $952(8.8)$ & $3,907(8.4)$ & 0.066 \\
\hline Overall NRDC & $3,197(9.0)$ & $1,040(9.6)$ & 4,237 (9.1) & 0.027 \\
\hline
\end{tabular}

Values are presented as number (\%).

NRDC, nonroutine discharge; $E D$, emergency department. 
SooJin Bae, et al.

Table 5. Univariate and multivariate logistic regression analyses of primary and secondary outcomes in the ED, ward, and overall

\begin{tabular}{|c|c|c|c|c|c|c|}
\hline & uOR & $95 \% \mathrm{Cl}$ & P-value & $\mathrm{aOR}$ & $95 \% \mathrm{Cl}$ & P-value \\
\hline \multicolumn{7}{|l|}{ ED } \\
\hline ED mortality & 1.146 & $0.973-1.351$ & 0.103 & 1.822 & $1.375-2.416$ & $<0.001$ \\
\hline \multicolumn{7}{|c|}{ Surviving patients in the ED } \\
\hline Admission & 0.932 & $0.888-0.977$ & 0.004 & 0.977 & $0.906-1.053$ & 0.546 \\
\hline Transfer & 1.137 & $1.057-1.222$ & $<0.001$ & 1.153 & $1.044-1.274$ & 0.005 \\
\hline NRDC & 1.059 & $0.982-1.143$ & 0.135 & 1.100 & $0.990-1.222$ & 0.077 \\
\hline \multicolumn{7}{|l|}{ Ward } \\
\hline Ward mortality & 1.387 & $1.213-1.587$ & $<0.001$ & 1.666 & $1.352-2.043$ & $<0.001$ \\
\hline \multicolumn{7}{|c|}{ Surviving patients in the ward } \\
\hline Transfer & 1.104 & $1.001-1.218$ & 0.048 & 1.355 & $1.188-1.546$ & $<0.001$ \\
\hline NRDC & 1.443 & $1.109-1.877$ & 0.006 & 1.477 & $1.046-2.069$ & 0.027 \\
\hline \multicolumn{7}{|l|}{ Overall } \\
\hline Overall mortality & 1.234 & $1.113-1.367$ & $<0.001$ & 1.680 & $1.408-2.005$ & $<0.001$ \\
\hline \multicolumn{7}{|c|}{ Surviving patients in the hospital } \\
\hline Overall transfer & 1.074 & $0.995-1.160$ & 0.066 & 1.311 & $1.179-1.457$ & $<0.001$ \\
\hline Overall NRDC & 1.086 & $1.009-1.169$ & 0.027 & 1.140 & $1.029-1.262$ & 0.012 \\
\hline
\end{tabular}

Values were adjusted for sex, systolic blood pressure, respiration rate, Glasgow coma scale score, excess mortality ratio-adjusted injury severity score, injury intention, injury mechanism, alcohol-related, emergency medical service usage, insurance, year of injury, and isolated traumatic brain injury.

$E D$, emergency department; $u O R$, unadjusted odds ratio; $\mathrm{Cl}$, confidence interval; aOR, adjusted odds ratio; NRDC, nonroutine discharge.
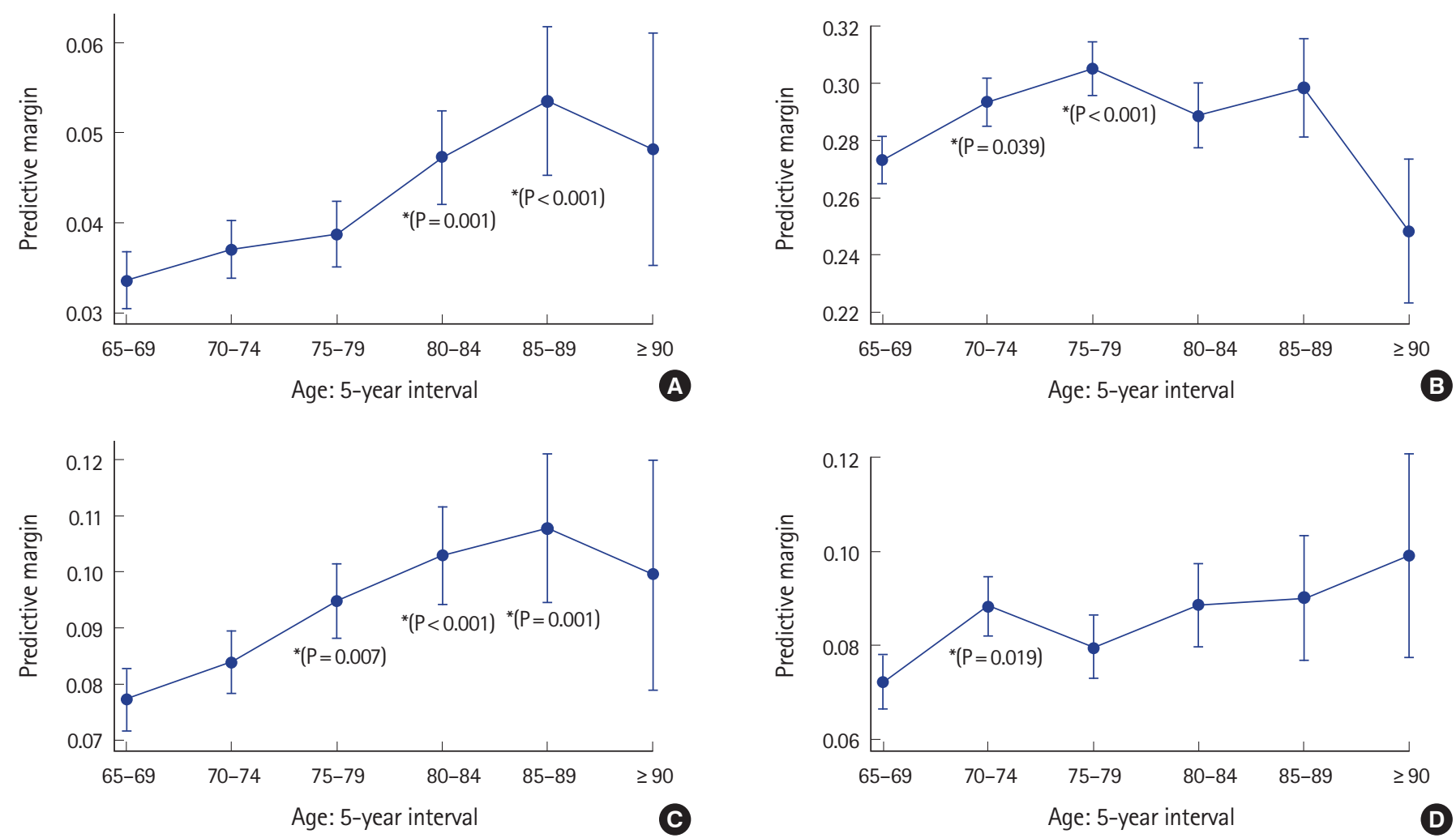

Fig. 2. Adjusted predictive margins of overall outcomes. (A) Mortality, (B) admission, (C) inter-hospital transfer, and (D) non-routine discharge. *Multiple comparisons against reference group (65-69 years).

95\% confidence interval $[\mathrm{Cl}], 1.408$ to $2.005 ; \mathrm{P}<0.001)$, interhospital transfer $(1.311 ; 95 \% \mathrm{Cl}, 1.179$ to $1.457 ; \mathrm{P}<0.001)$, and NRDC $(1.140 ; 95 \% \mathrm{Cl}, 1.029$ to $1.262 ; \mathrm{P}=0.012)$ were also significant.
In the stratified multivariate logistic analysis, the effect of aging on mortality and interhospital transfer remained significant when stratified by timing of treatment, but the effect of aging on 
NRDC showed different results for the ED and ward admissions. TBI patients who visited the ED had no significant differences in adjusted odds of NRDC (1.100; 95\% Cl, 0.990 to $1.222 ; \mathrm{P}=0.077)$, but when admitted to the ward, TBI patients showed significant differences in adjusted odds of NRDC $(1.477 ; 95 \% \mathrm{Cl}, 1.046$ to $2.069 ; P=0.027)$.

Fig. 2 shows the results of the multivariate logistic regression analysis of overall outcomes, followed by additional multiple comparisons treating age as an ordinal categorical variable at a 5-year interval. There was a statistically significant increase in mortality in the groups aged 80 to 84 years and 85 to 89 years, compared to the reference age group (65 to 69 years). Admission rates increased in the groups aged 70 to 74 years and 75 to 80 years. Moreover, interhospital transfers increased in the groups aged 75 to 79 years, 80 to 84 years, and 85 to 89 years. The NRDC rate only increased in the group aged 70 to 74 years.

\section{DISCUSSION}

The aging of the world's population is progressing at a rapid pace. By 2025, the number of people aged $\geq 65$ years in South Korea is expected to exceed $20 \%$ of the country's population. 'Despite the trend of increased longevity among the aging population, older people appear to be more prone to injuries such as TBI. ${ }^{5}$ Between older and younger people, their biological characteristics, major mechanisms of injury, and preexisting comorbidities still differ with regard to complications, functional outcomes, and mortality. ${ }^{8}$

Several studies have focused on comparing older and younger age groups in terms of demographic changes. However, most of the comparisons are often between patients aged $<65$ and $\geq 65$ years. Moreover, these studies have found no mortality differences in the older population. This, therefore, calls the need for comparing and analyzing mortality differences with other population subgroups such as the super-geriatric population, which is emerging as a new age group.

As TBI is prevalent among older people, this study aimed to determine and compare the effect of aging on mortality and medical resource utilization between geriatric and super-geriatric patients with TBI. We found that super-geriatric TBI patients had higher overall mortality but lower rates of medical resource utilization (interhospital transfer or NRDC) than did geriatric TBI patients. Furthermore, in the stratified analysis, there were no significant differences in the NRDC rate for all stratifications of treatment timing of (the ED and ward admission), but mortality and interhospital transfer remained significant for all stratifications.

Consistent with our results, previous studies have demonstrat- ed that age is a major independent predictor of mortality in TBI. Mosenthal et al. ${ }^{9}$ found that most of the causes of increased mortality could be attributed to aging and that part of the increase in mortality could be explained by the type of complications in TBI or the severity of brain damage.

Some previous studies also showed no difference in long-term mortality after TBI between the geriatric and super-geriatric groups, whereas short-term mortality has been reported to be significantly higher in the super-geriatric group. ${ }^{10}$ However, these results differ from our findings, which showed that mortality was consistently high among the study population regardless of the timing of treatment.

In terms of medical resource utilization, prior studies have revealed that the presence of a do-not-resuscitate (DNR) order, TBI severity, intensive care, and comorbidities are among the factors affecting mortality after TBI. ${ }^{11,12}$ Moreover, of the factors affecting mortality, the controllable ones mainly include the use of early DNR orders and the selective use of medical resources, including intensive care.

The use of early DNR orders among patients with severe TBI varies by the hospital and type of hospital. ${ }^{13}$ However, Hakim et al. reported that DNR orders were being signed at a more rapid pace for patients aged $\geq 75$ years, regardless of the severity of the disease. This factor was found to be associated with a secondary mortality increase. ${ }^{14}$ Turgeon et al. ${ }^{15}$ have also identified a factor for premature death that is associated with the withdrawal of life-sustaining therapy. Our study did not investigate the presence of DNR orders due to data limitations and was thus only able to reveal the difference in mortality rates in the ED and based on the combination of in-hospital stays between the geriatric and super-geriatric groups. We were unable to reveal the relationship between the presence of DNR orders and mortality rates.

Our finding that super-geriatric TBI patients were more likely to have lower rates of medical resource utilization (interhospital transfer or NRDC) than geriatric TBI patients was also similar to those of other studies. Susman et al. and Mosenthal et al. found that increase in hospitalization and hospital mortality rates in patients aged $\geq 65$ years. ${ }^{8,9}$ However, the results of our study did not show any difference in hospitalization between the geriatric and super-geriatric groups.

According to the Eastern Association for the Surgery of Trauma, aggressive treatment is recommended for geriatric patients with severe TBI to help them recuperate and return to the daily normal lives. ${ }^{16}$ Elderly patients have reported excellent responses to aggressive resuscitation. ${ }^{17,18}$ However, people with severe injury (injury severity score of $>30$ ) were reported to use a relatively small amount of intensive care unit resources, which was found 
to be associated with an increase in mortality. ${ }^{19}$ In addition, Hanson et al. ${ }^{20}$ and Pronovost et al. ${ }^{21}$ found a 40\% mortality reduction when intensivist-model intensive care units were applied to critically ill adults. According to the TBI treatment guidelines, TBI in older people requires intensive care so that better results can be achieved. ${ }^{16}$ Besides, in a comparative study of younger (aged $<65$ years) and older people, the older group reported better treatment and better prognosis when treated in the intensive care unit. However, older people tended to receive less aggressive treatment than younger people, and this was shown to have an impact on later outcomes.

As observed in previous studies, aggressive and intensive care is of paramount importance to the elderly with TBI. The rate of receiving intensive care can be seen as a form of a medical resource utilization rate. This study attempted to identify differences in the discontinuation of these treatments, i.e., NRDC in the elderly. Several previous studies have shown that there are agerelated differences in various medical resource utilization rates. However, little has been investigated about the difference in NRDC rates based on age, so this study particularly attempted to find the difference in NRDC rate between the geriatric and super-geriatric groups in each phase of treatment. Surprisingly, significant differences in NRDC rate between both patient groups were only found in the ward, but no differences were found in the ED. These results could be associated with the nature of the patients' behavior, as patients or families tend to utilize more medical resources in the emergent phase.

Chang et al. ${ }^{22}$ stated that ethnic and cultural differences affect the patient's disposition. Elderly Hispanic patients and black patients were discharged to their homes more often than white patients were. This could be because the elderly play a central role in Hispanic culture, in which elderly people are given a great deal of respect. Financial resources were also found to have an impact on disposition. Black patients were found to have relatively smaller incomes than white patients, limiting their choices as regards transferring to a more specialized rehabilitation hospital. In addition, those receiving medical assistance had a low rate of transferring to a specialized rehabilitation hospital. Furthermore, Thompson et al. ${ }^{12}$ and McKevitt et al. ${ }^{23}$ reported that older people have a lower rate of transferring to a specialized rehabilitation hospital than younger people.

In this study, super-geriatric TBI patients experienced 1.311 times more interhospital transfers after hospitalization than did geriatric $\mathrm{TBI}$ patients (adjusted odds ratio, $1.311 ; 95 \% \mathrm{Cl}, 1.179$ to 1.457 ; $P<0.001)$. However, the reasons for interhospital transfers and type of destination hospitals were not known due to limited data.

Elderly people are less likely to visit the outpatient department after discharge and have less money to pay for rehabilitation. They also tend to be readmitted more often as they are more likely to experience NRDC. This suggests that inequality in the medical resource utilization rate do exist among different age groups. ${ }^{12,24}$

Consistent with the findings of other studies, this research also found that aging was a significant factor for mortality, even in geriatric and super-geriatric TBI patients. However, age as an absolute component of mortality should be interpreted with caution because other factors such as inequality in medical resource utilization rates according to age cannot be ruled out. Thus, further studies with more focus on the interaction between age and medical resource utilization are required, and reliable analytical methods need to be developed for these studies.

In summary, we found that super-geriatric TBI patients had a significantly higher risk-adjusted overall mortality rate and a lower medical resource utilization rate than geriatric TBI patients. Furthermore, in the stratified analysis, there were no significant differences in NRDC rate between both groups when stratified by the timing of treatment, but mortality and interhospital transfer remained significant for all stratifications of treatment timing. Further study on age-related inequalities in health care is recommended, especially with regard to the treatment of geriatric patients.

\section{CONFLICT OF INTEREST}

No potential conflict of interest relevant to this article was reported.

\section{ACKNOWLEDGMENTS}

This research was supported by the Research of Korea Centers for Disease Control and Prevention.

\section{REFERENCES}

1. Statistics Korea. Population projections and summary indicators [Internet]. Daejeon: Korean Statistical Information Service; 2019 [cited 2020 Mar 27]. Available from: http://kosis. $\mathrm{kr} / \mathrm{statHtml} /$ statHtml.do?orgld = 101\&ttblld = DT_1BPA002\&la nguage $=$ en .

2. Statistics Korea. Population status and prospects of the world and Korea in 2019 [Internet]. Daejeon: Statistics Korea; 2019 [cited 2020 Apr 22]. Available from: http://kostat.go.kr/portal/ korea/kor_nw/1/1/index.board?bmode $=$ read\&taSeq $=377226$.

3. Rothweiler B, Temkin NR, Dikmen SS. Aging effect on psychosocial outcome in traumatic brain injury. Arch Phys Med Re- 
habil 1998;79:881-7.

4. Mosenthal AC, Livingston DH, Lavery RF, et al. The effect of age on functional outcome in mild traumatic brain injury: 6-month report of a prospective multicenter trial. J Trauma 2004;56:1042-8.

5. Taylor CA, Bell JM, Breiding MJ, Xu L. Traumatic brain injuryrelated emergency department visits, hospitalizations, and deaths - United States, 2007 and 2013. MMWR Surveill Summ 2017;66:1-16.

6. Hukkelhoven CW, Steyerberg EW, Rampen AJ, et al. Patient age and outcome following severe traumatic brain injury: an analysis of 5600 patients. J Neurosurg 2003;99:666-73.

7. Thompson HJ, McCormick WC, Kagan SH. Traumatic brain injury in older adults: epidemiology, outcomes, and future implications. J Am Geriatr Soc 2006;54:1590-5.

8. Susman M, DiRusso SM, Sullivan T, et al. Traumatic brain injury in the elderly: increased mortality and worse functional outcome at discharge despite lower injury severity. J Trauma 2002;53:219-23.

9. Mosenthal AC, Lavery RF, Addis M, et al. Isolated traumatic brain injury: age is an independent predictor of mortality and early outcome. J Trauma 2002;52:907-11.

10. Mclntyre A, Mehta S, Aubut J, Dijkers M, Teasell RW. Mortality among older adults after a traumatic brain injury: a meta-analysis. Brain Inj 2013;27:31-40.

11. Thompson HJ, Rivara FP, Jurkovich GJ, Wang J, Nathens AB, MacKenzie EJ. Evaluation of the effect of intensity of care on mortality after traumatic brain injury. Crit Care Med 2008;36: 282-90.

12. Thompson HJ, Weir S, Rivara FP, et al. Utilization and costs of health care after geriatric traumatic brain injury. J Neurotrauma 2012;29:1864-71.

13. Dean D, Martinez MS, Newgard CD. Variability in early do not attempt resuscitation orders among patients with serious traumatic brain injury. Acad Emerg Med 2015;22:54-60.

14. Hakim RB, Teno JM, Harrell FE Jr, et al. Factors associated with do-not-resuscitate orders: patients' preferences, prognoses, and physicians' judgments. SUPPORT Investigators. Study to understand prognoses and preferences for outcomes and risks of treatment. Ann Intern Med 1996;125:284-93.

15. Turgeon AF, Lauzier F, Simard JF, et al. Mortality associated with withdrawal of life-sustaining therapy for patients with severe traumatic brain injury: a Canadian multicentre cohort study. CMAJ 2011;183:1581-8.

16. Jacobs DG, Plaisier BR, Barie PS, et al. Practice management guidelines for geriatric trauma: the EAST Practice Management Guidelines Work Group. J Trauma 2003;54:391-416.

17. Scalea TM, Simon HM, Duncan AO, et al. Geriatric blunt multiple trauma: improved survival with early invasive monitoring. J Trauma 1990;30:129-34.

18. McKinley BA, Marvin RG, Cocanour CS, Marquez A, Ware DN, Moore FA. Blunt trauma resuscitation: the old can respond. Arch Surg 2000;135:688-93.

19. Taylor MD, Tracy JK, Meyer W, Pasquale M, Napolitano LM. Trauma in the elderly: intensive care unit resource use and outcome. J Trauma 2002;53:407-14.

20. Hanson CW 3rd, Deutschman CS, Anderson HL 3rd, et al. Effects of an organized critical care service on outcomes and resource utilization: a cohort study. Crit Care Med 1999;27: 270-4.

21. Pronovost PJ, Angus DC, Dorman T, Robinson KA, Dremsizov $\Pi$, Young TL. Physician staffing patterns and clinical outcomes in critically ill patients: a systematic review. JAMA 2002;288: 2151-62.

22. Chang PF, Ostir GV, Kuo YF, Granger CV, Ottenbacher KJ. Ethnic differences in discharge destination among older patients with traumatic brain injury. Arch Phys Med Rehabil 2008;89: 231-6.

23. McKevitt EC, Calvert $E_{1} \mathrm{Ng} \mathrm{A}$, et al. Geriatric trauma: resource use and patient outcomes. Can J Surg 2003;46:211-5.

24. Frankel JE, Marwitz JH, Cifu DX, Kreutzer JS, Englander J, Rosenthal M. A follow-up study of older adults with traumatic brain injury: taking into account decreasing length of stay. Arch Phys Med Rehabil 2006;87:57-62. 